Journal of Engineering and Applied Sciences 13 (4): 910-913, 2018

ISSN: 1816-949X

(C) Medwell Journals, 2018

\title{
A Study on the Performance of Sound Fire Extinguisher by Anti Resonance
}

\author{
Eun-Young Yi, Uk-Jin Song and Myung-Jin Bae \\ Department of Information and Telecommunication Engineering, Soong-sil University, \\ Sang-doro, Dong Jak-gu, 369 Seoul, Korea
}

\begin{abstract}
The causes of fire can vary greatly. Combustion by gas, combustion by burning solid and combustion by explosion. In the everyday life there are many fires in the singer range in the kitchen. If the gas range is ignited by a person or if the person is not aware that the gas is unburned or that the pot is overflowing with gas, the danger of the gas leaking may occur. At this time, a fire is not effective in taking any measures. The purpose of this study was to investigate the effect of sound fire extinguisher fire has a characteristic that the extent of damage increases as time goes by. When an object rubs its kinetic energy into heat energy, the stronger the friction, the more heat it generates. To burn an object, it needs de-matter and temperature above the flash point and sufficient oxygen. Fire extinguishing methods, chilled fire extinguishing methods and extinguishing fire extinguishing methods are examples of fire extinguishing methods. The elimination fire extinguishing method is a method of eliminating the debris and further preventing the fire from spreading. This is the best way to do when there is no equipment to turn off the lights. It is the first method to be used when a fire occurs. Applying the wrong fire extinguishing method at the beginning of the fire can be very dangerous. This study is a study of fire evolution using fire extinguisher to evolve fire. It is an study about the early evolution of fire that occurs in our everyday life as it improves the removal fire extinguishing method by using anti-communications. Experiments on the disappearance of the flame and the theoretical background based on this experiment are discussed. The background is based on the anti-air bombardment which enables efficient fire evolution with less power.
\end{abstract}

Key words: Anti resonance, theoretical back ground, fire, heat energy, less power, anti-communications

\section{INTRODUCTION}

Fire has a characteristic that the extent of damage increases as time goes by. In Winter, fire is more frequent and firefighters become more busy. The principle of fire on an object is that when the object rubbes, kinetic energy is converted into thermal energy. The stronger the frictional force, the more heat it generates. The minimum temperature at which the substance burns is different and the ignition point is different. Some objects ride at temperatures as low as $60^{\circ} \mathrm{C}$ and some objects do not burn at temperatures above $1000^{\circ} \mathrm{C}$. If the temperature is above the ignition point, it does not ignite. Burning of objects is combustion. To burn an object, it is necessary to have deaerated substances, temperatures above the flash point and sufficient oxygen. When burning wood, it is better to build a lot of space for air into the building by stacking it in a zigzag rather than just stacking firewood. In Winter, the atmosphere is dry and the humidity in the air is low. If there is a large amount of moisture in the air, the ignition point of the object becomes higher. On the contrary if the air is dried, the ignition point of the object becomes lower. Three conditions are required for combustion. When the fire is extinguished, I use a method to block three conditions. The fire extinguishing method, the cooling fire extinguishing method and the extinguishing fire extinguishing method are available. When the oxygen is cut off, the pyrolysis method does not generate combustion. Cooling extinguishes the ambient temperature below the flash point. The way to spray water is representative. But when the hot water is sprayed, the fire goes out well. The hotter the water, the faster it turns into steam. The elimination fire extinguishing method is a method of eliminating the debris and further preventing the fire from spreading. This is the best way to do when there is no equipment to turn off the lights. It is the first method to be used when a fire occurs. I found a fire but if it is close to explosive or flammable material such as gaso line that is easily ignited at low temperatures, it must be

Corresponding Author: Myung-Jin Bae, Department of Information and Telecommunication Engineering, Soong-sil University, Sang-doro, Dong Jak-gu, 369 Seoul, Korea 
removed before it can be prevented from leading to a large fire. The most important thing in suppressing a fire is 'quick action'. Seasonally, when the humidity is the lowest, the probability of occurrence in the order of Winter, Spring, Autumn and Summer is lower (Eun-young and Myung-Jin, 2015). There are many reasons for the fire and the materials that cause the fire are also very diverse. As the cause of the fire varies widely, the method of extinguishing it must be different. Therefore, applying the wrong method of extinguishing at the beginning of the fire can be very dangerous. Previous studies related to flame have been based on the type of flame used in fireworks display and there have been studies on lifecycle related to the generation, growth, aging process and extinction of non-particles moving by computer simulation (Cho et al., 2014). The use of a fire extinguisher is somewhat difficult to use because there are disadvantages such as pulling the safety pin, pulling the handle and lever, releasing the remaining gas immediately after use.

In fact there is no trace of using a hydrator or an indoor fire hydrant at the fire scene. New countermeasures against existing fire extinguisher (Young-Sun, 2015) problems are required. On July 27, 2015, Seth Robertson and Viet Tran, engineers at Fairfax George Mason University, Virginia, confirmed the technology development announcement of the US Department of Defense in July 2012 (Anonymous, 2015). It opened the possibility of suppressing the fire by sound through the image of fire extinguisher. This study is a study on sound wave control of sound extinguisher. Set the distance between sound fire extinguisher and flame (flame) to $50 \mathrm{~cm}$ and control the change of volume velocity of sound wave. This is a study to maximize the fire evolution in the early stage of the fire while limiting the power of the sound fire extinguisher to a minimum.

\section{MATERIALS AND METHODS}

Breath of candles: As a basic experiment for fire suppression using sound fire extinguisher, we use candle light. Figure 1 shows the relationship between the flexibility of the surface of the fire, i.e., the portion of permeability and the fuel supply core.

As shown in Fig. 1, the state of $B$ should be maintained when the state of the flame changes from $A$ to $\mathrm{B}$ in order to shake the candle by the sound wave input.

Sound extinguisher sound wave energy radiation: A sound extinguisher is a device that uses a vibration of a

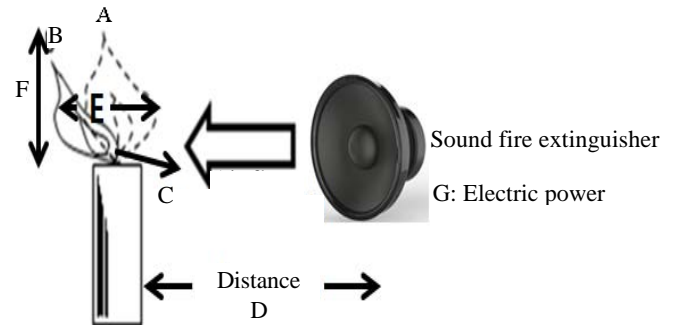

Fig. 1: Experiment of breathing through a candle

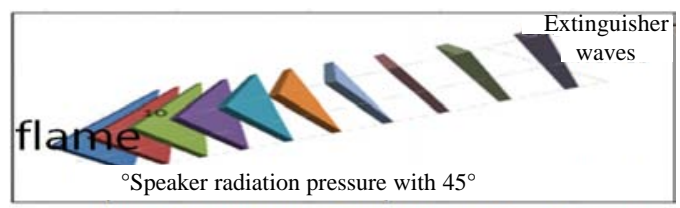

Fig. 2: Changes in sound velocity of sound extinguisher sound waves

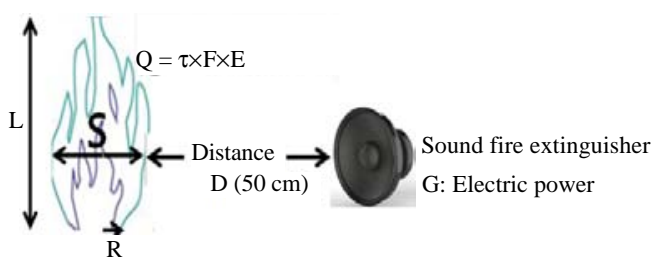

Fig. 3: Sound digester evolution experiment

sound wave to evolve a fire. Ignite the fire I fire a sound wave at a distance of about $50 \mathrm{~cm}$ from the speaker to the flame (flame) which is very close.

At this time, the operation of the loudspeaker produces the air-tightness of the air. It is input to the flame as a $45^{\circ}$ angle and is used to remove the flame. At the beginning of the speaker operation, a sound wave of a volume velocity is outputted and in the latter half, a sound wave which significantly lowers the volume velocity is generated (Fig. 2).

Figure 3 shows the sound pressure of a speaker in a sound extinguisher acts as the surface radiant energy of the speaker. The magnitude of this surface radiant energy should affect the total radiant heat $Q$ that the spark is generating. In addition, to prevent the flame from continuing to burn out, it is necessary to draw out the oxygen that is flowing in from outside. This is a feature of sound fire extinguishers. At this time, one of the factors determining the characteristics of the flame is the ratio of total radiant heat to the type of material. It depends on methanol, Liquefied Natural Gas (LNG) butane, gasoline, benzene:

$$
\mathrm{E}=\frac{\mathrm{R} \times \mathrm{M} \times \mathrm{H}_{0}}{3.14 \mathrm{D}^{2} \times \mathrm{t}}\left[\frac{\mathrm{kJ}}{\mathrm{m}^{2} \mathrm{sec}}\right]
$$


Where:

$\mathrm{E}=$ Surface radiant energy

$\mathrm{R}=$ The Radiation rate of the heat of combustion (dimensionless); 0.3 (Rupture below set pressure of pressure relief device); 0.4 (Rupture above set pressure of pressure release device)

$\mathrm{H}_{0}=$ Net heat of combustion $\mathrm{k}_{\mathrm{j}} / \mathrm{k}_{\mathrm{g}}(\mathrm{Kim}$ et al., 2015)

The heat of combustion is determined by the substance causing the fire. $\mathrm{R}$ is determined by the magnitude of the sound pressure during operation of the speaker and is usually set between 0.3 and 0.4 . The net heat of combustion is determined by dividing the energy of the material generating the flame of the fire by the mass of the material (Kim et al., 2015).

\section{RESULTS AND DISCUSSION}

\section{Flame heat energy radiation modeling:}

$$
\mathrm{R}=\mathrm{p} \frac{\mathrm{I}}{\mathrm{S}}=\mathrm{p} \frac{\mathrm{L}}{4 \pi \mathrm{r}^{2}}
$$

Where:

$\mathrm{L}=$ View of the flame pillar

$\mathrm{S}=$ The surface area of a sphere

$$
\lambda=\frac{\mathrm{v}}{\mathrm{f}}=\frac{340\left(\frac{\mathrm{m}}{\mathrm{sec}^{2}}\right)}{\text { Speaker operating frequency }}=\frac{340}{100}=3.4 \mathrm{~m}
$$

If $\lambda_{\gg} L$ : the speaker's sound pressure is diffracted and placed on the back of the flame. $\lambda / 2$ half wavelength parallel resonance, sound pressure (maximum), volumetric speed (minimum):

$$
\begin{aligned}
& \frac{3.4 \mathrm{~m}}{2}=1.7 \mathrm{~m}, 1.7-0.5 \mathrm{~m} \\
& \text { (between the speaker and the flame) }=1.2 \mathrm{~m} \\
& \mathrm{~T}=\frac{1}{\mathrm{f}}=\frac{1}{100}=0.01 \mathrm{sec} 0.01 \times 500=5 \mathrm{sce}
\end{aligned}
$$

The sound pressure change in the speaker occurs 500 times in $5 \mathrm{sec}$. At the beginning of the sound extinguisher operation, the impedance of the portion of Fig. 4 behind the flame is minimized. After a few seconds, the impedance of the part of Fig. 4 becomes maximum. The change in the impedance of the portion is a major factor indicating the state change of the flame.

Figure 5 shows the series resonance and the parallel resonance principle which are the causes of the flame spread at the early stage of fire evolution during the operation process of the sound fire extinguisher. Figure 5 shows the resonance circuit connected in parallel with the piezo-electric equivalent circuit: resistance, reactance component and capacitance component of the material when the cause of the flame spread at the early stage of fire evolution during the operation process of the sound fire extinguisher (A) is the resonance. The cause of this can be found in Fig. 5(A) when the impedance of the part of Fig. 4(A) corresponding to the back of the flame is minimized. It represents the initial state in which a sound extinguisher is placed into a flame and enters a sound wave, at which time the volume velocity of the flame is at its maximum, so that, it instantaneously increases to the maximum of the flame. After a few seconds, due to the characteristics of the sound extinguisher system, the point of Fig. 4)A) becomes the half-resonance point where the point impedance becomes the maximum and the point of Fig. 4(A) becomes infinite impedance. It plays a supporting role and removes the flame.

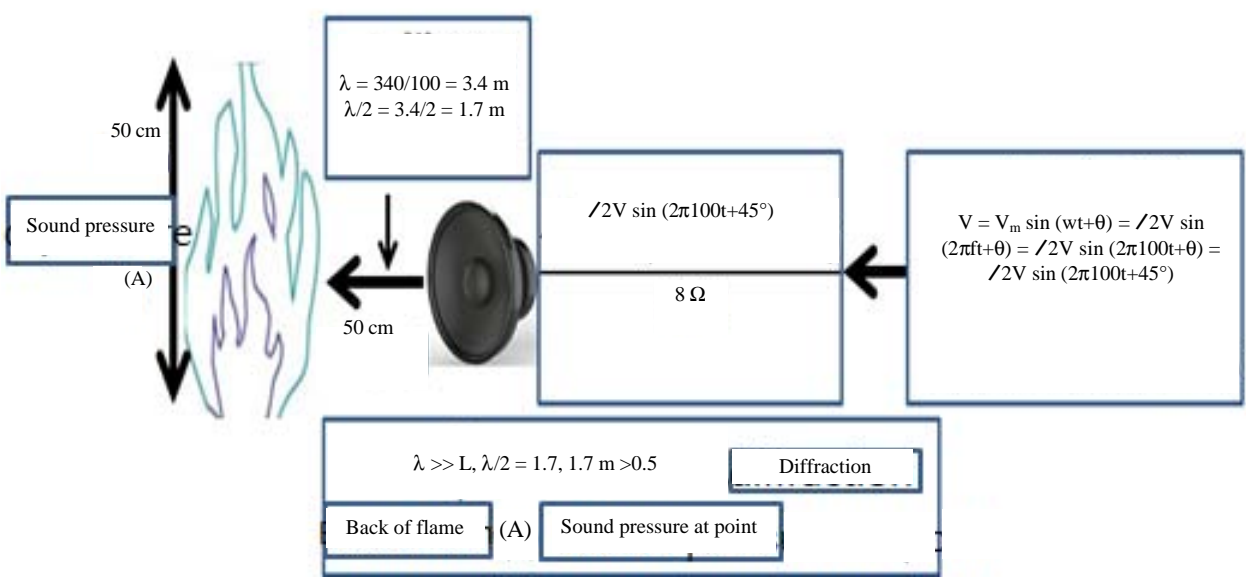

Fig. 4: Electrical input, distance and sound pressure relationship of sound extinguisher experiment 


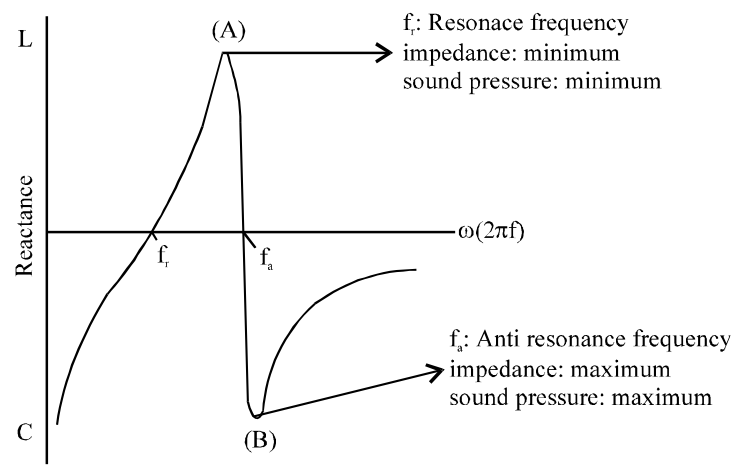

Fig. 5: Resonance characteristics of sound extinguisher

\section{CONCLUSION}

It is important to prevent fire from being destroyed as a way to reduce the damage of life property in case of fire. The type of fire damage is caused by smoke but the primary cause is combustion by flame. The direction of the fire is the most threatening and most important to the person evolving the fire. This study proposes a sound extinguisher as an alternative to control the direction of the fire. The elimination fire extinguishing method is a method of eliminating the debris and further preventing the fire from spreading. This is the best way to do when there is no equipment to turn off the lights. It is the first method to be used when a fire occurs. Applying the wrong fire extinguishing method at the beginning of the fire can be a very dangerous situation.

This study is a study on fire evolution using fire extinguisher to evolve fire. It is a study about the early evolution of fire that occurs in our everyday life. The volumetric speed of the flame is converted to the point at which the impedance around the flame (flame) is maximized using the acoustic impedance. This serves to prevent sound waves from being continuously transmitted from the sound fire extinguisher and to remove the flame. Experiments on the disappearance of the flame and the theoretical background based on this experiment are discussed. This study is a study on the principle that sound fire extinguisher can evolve fire early regardless of kinds of gas materials. The background is based on the anti-air bombardment which enables efficient fire evolution with less power.

\section{REFERENCES}

Anonymous, 2015. Pump up the bass to douse a blaze: Mason students. George Mason University, Fairfax, Virginia.

Cho, C., K. Kim and C. Jeong, 2014. Fireworks modeling technique based on particle tracking. J. Inst. Electron. Inf. Eng., 51: 102-109.

Eun-Young, Y. and B. Myung-Jin, 2015. Study on candlelight extinguish by focused transducer. Acoustical Society of Korea, South Korea.

Kim, K.C., S.J. Kang, M.Y. Kim, W. Kim and K.C. Kwon, 2015. [Experimental study on impinging spray behavior with direct injection spark ignition injector (In Korean)]. Proc. Korean Soc. Autom. Eng. Conf., 2005: 9-14.

Young-Sun, C., 2015. When you turn off charcoal, Why use soil instead of water?. Chosun Media Co. Ltd., Korea. https://translate.google.com/translate?hl=en\& $\mathrm{sl}=\mathrm{ko \& u}=\mathrm{http} / /$ newsteacher.chosun.com/site/data/ html_dir/2015/01/20/2015012000390.html\&prev=sear ch. 